\title{
A LINGUAGEM JURÍDICA E A NECESSIDADE DE SUA SIMPLIFICAÇÃO PARA O ACESSO À JUSTICA E CIDADANIA
}

\author{
Ionara Fonseca da Silva Andrade ${ }^{1}$ \\ Patrícia de Amorim Rêgo ${ }^{2}$ \\ Maria Claudia da Silva Antunes de Souza ${ }^{3}$
}

\section{RESUMO}

As ciências da Linguagem e Jurídicas são constructos sociais que se fundamentam nas necessidades dos sujeitos em sociedade. A pesquisa tem como objetivo trazer a reflexão da importância da simplificação da linguagem jurídica para a democratização do Direito e o acesso à justiça. O método utilizado é o indutivo por meio de pesquisas bibliográficas. Conclui-se que a pratica do Direito associado aos estudos Linguísticos possibilitam ao poder judiciário manter uma relação dialógica com a sociedade e que esta aproximação tende a conferir maior grau de legitimidade ao poder judiciário e o cidadão só tem a se beneficiar com esta interação.

Palavras-chave: Linguagem. Ciências jurídicas. Simplificação. Direito. Acesso à Justiça.

\section{THE LEGAL LANGUAGE AND THE NEED FOR ITS SIMPLIFICATION FOR ACCESS TO JUSTICE AND CITIZENSHIP}

\begin{abstract}
Language and Legal Sciences are social constructs based on the needs of individuals in society. The research aims to reflect on the importance of simplifying the legal language for the democratization of Law and access to justice. The method used is inductive through bibliographic research. It is concluded that the practice of Law associated with Linguistic studies allows the judiciary to maintain a dialogical relationship with society and that this approach tends to confer a greater degree of legitimacy to the judiciary and the citizen can only benefit from this interaction.
\end{abstract}

Keywords: Language. Legal sciences. Simplification. Right. Access to justice.

\footnotetext{
${ }^{1}$ Doutoranda pela Universidade do vale do Itajaí, (UNIVALE). Mestre em Linguagem e Identidade pela Universidade Federal do Acre (UFAC). Bacharel em Direito pelo Centro Universitário (U:VERSE), Licenciatura em Letras pela (UERN). Docente nas áreas de Direito Civil, Linguagem e Metodologia. ionarauern@ gmail.com. Orcid: https://orcid.org/0000-0002-6444-102X.

${ }^{2}$ Doutoranda no Programa de Ciências Jurídicas pela Universidade do Vale de Itajaí - UNIVALI. Mestra em Direito pela Universidade Federal de Santa Catarina -UFSC. Procuradora de justiça do Ministério Público do Estado do Acre. https://orcid.org/0000-0002-8264-4277.

${ }^{3}$ Doutora e Mestre em Derecho Ambiental y de la Sostenibilidad pela Universidade de Alicante - Espanha. Mestre em Ciência Jurídica pela Universidade do Vale do Itajaí - UNIVALI. Professora Permanente no Programa de Pós-Graduação Stricto Sensu em Ciência Jurídica, nos cursos de Doutorado e Mestrado, e na Graduação no Curso de Direito, ambos da Universidade do Vale do Itajaí - UNIVALI. Coordenadora do Grupo de Pesquisa "Direito Ambiental, Transnacionalidade e Sustentabilidade" cadastrado no CNPq/EDATS/UNIVALI. Advogada. E-mail: mclaudia@univali.br. Orcid: https://orcid.org/0000-0002-81181071.
} 


\section{INTRODUÇÃO}

Diante do atual contexto globalizante o qual estamos vivenciando, percebe-se, que as relações entre linguagem e Direito estão experimentando profundas modificações provenientes das consequências da globalização e, consequentemente, dos recentes avanços tecnológicos. O processo de comunicação vem tornando-se cada vez mais ágil e a informação transforma-se em uma importante ferramenta de acesso à justiça. Nesta perspectiva, tona-se salutar a necessidade de reconhecer à importância da simplificação da linguagem jurídica, visto que, este processo é imprescindível para interação e efetivação da comunicabilidade dos indivíduos que estão inseridos na sociedade, possibilitando assim, a democratização e pluralização de acesso à justiça.

Com essas as novas demandas provenientes da globalização, torna-se, portanto, crucial, resinificar a relação entre Direito e Linguagem. É comum no ambiente forense, deparamo-nos, constantemente, com textos jurídicos demasiadamente técnicos, arcaísmos rebuscados e juridiquês de difíceis compreensão, o que têm proporcionado inúmeras discussões e, consequentemente, a insatisfação da sociedade leiga que busca o Poder Judiciário com o intuito de ter a concretização e acesso à justiça.

Ao debruçarmos sobre a temática da linguagem jurídica, ressaltamos que a nossa pretensão é contribuir com a discussão entre a Linguagem e Ciência Jurídica, porém, em virtude da abrangência e complexidade da temática não temos por objetivo exauri-la. Acreditamos que a linguagem jurídica é um processo comunicativo que deve ser visto como acessível para aqueles que dela necessitam fazer uso. Neste sentido, a comunidade jurídica, em especial, os magistrados têm o ônus de facilitar a comunicação à sociedade civil.

Assim, entendemos que na prestação jurisdicional, faz-se necessário uma linguagem clara, objetiva, porém, importa ressaltar que não desconsideramos que, por muitas vezes, os termos técnicos são necessários a qualquer área de atuação, contudo, é imprescindível que em situação de comunicação jurídica a linguagem não possibilite margem à ambiguidade na interpretação e, consequentemente, o distanciamento do Direito a sociedade.

Acreditamos que a atividade jurisdicional se torne legítima esta deve ser vista pela sociedade como um caminho de realização e efetividade da Justiça, não como algo obstrutivo, incompreensível e inacessível. Neste sentido, para o problema de pesquisa, elencamos o seguinte questionamento: A sociedade segue fundamentalmente da linguagem, nesta 
perspectiva, por que alguns magistrados fazem questão que a linguagem jurídica fique restrita ao próprio meio jurídico, dificultando a efetividade de compreensão a sociedade?

Objetivo do presente artigo é conscientizar a comunidade cientifica sobre a importância da simplificação da linguagem jurídica para uma real democratização do Direito e o acesso à justiça.

A relevância da pesquisa dar-se-á em virtude da necessidade de tonar em evidencia o debate da comunidade cientifica a importância da simplificação da linguagem jurídica. Desta forma, estamos a empenhar-nos, cada vez mais, para que o poder judiciário desperte para a necessidade de se deixar de lado o aspecto monólogo das suas sentenças para exercitar a necessidade de por em pratica os aspectos que envolvem a relação dialógica da linguagem, aproximando assim a Justiça a todos os cidadãos.

Para o procedimento metodológico, buscamos suporte teórico nas fases da Pesquisa Científica desenvolvidas por (PASOLD, 2015). A escolha do método é o indutivo ${ }^{4}$ por meio de pesquisas bibliográficas. No primeiro momento, apresenta-se breve ponderação sobre Linguagem e Direito, na sequência, desenvolvemos sobre o tecnicismo da linguagem jurídica e, por fim, as considerações finais.

\section{2 - BREVES PONDERAÇÕES ENTRE LINGUAGEM E DIREITO.}

Ao inter-relacionarmos a história das ciências da Linguagem e a do Direito torna-se inegável que são constructos sociais que se entrelaçam e se complementam. Como bem pontua Xavier (2002. p. 01) “O Direito é, por excelência, entre as que mais o sejam, a ciência da palavra". Desta forma, não há como falar em Direito sem nos referirmos à linguagem, visto que, esta é o principal instrumento em que os construtores ${ }^{\mathbf{5}}$ do Direito utilizam para se fazerem compreendidos.

A linguagem é desenvolvida por estes profissionais como um "cartão de visita" para que possam interagir em sociedade. Torna-se, portanto, irrefutável a compreensão de que para

\footnotetext{
4 "MÉTODO INDUTIVO: base lógica da dinâmica da Pesquisa Científica que consiste em pesquisar e identificar as partes de um fenômeno e coleciona-las de modo a ter uma percepção ou conclusão geral".

5 A denominação "Construtores do Direito" é vista aqui como uma escolha necessária a substituição da expressão mecanicista "Operadores do Direito", pois, entendemos que diante das transformações sociais, ideológicas, políticas e jurídicas em que a sociedade contemporânea vem se estruturando, há necessidade da ressignificação de conceitos historicamente construídos. Acreditamos que esta ressignificação semântica deve ser propagada como fins pedagógicos com o propósito de produzir uma reflexão crítica pautada nos aspectos dialógicos e interacionais tanto nas ciências da Linguagem quanto do Direito.
} 
efetuarmos de forma satisfatória o processo de comunicação jurídica, devemos compreender as dimensões da linguagem.

A linguagem e o Direito são áreas de conhecimento que fazem parte da vida dos sujeitos em sociedade, são produtos de construção historica, sócio-cultural, que devem ser analisados sob os aspectos de representações imagéticas discursivas, ideologia e poder. Tanto a ciencia da linguagem quanto a jurídica são substanciais para que possamos atingir à efetivação do acesso à justiça, visto que, são intrumentos oportunos para que os sujeitos possam engajarem socialmente.

Como bem preleciona Castanheira, (1993, p. 90), “O Direito é linguagem e terá que ser considerado em tudo e por tudo como uma linguagem. O que quer que seja e como quer que seja, o que quer que ele se proponha e como quer que nos toque, o Direito é-o numa linguagem e como linguagem, propõe-se sê-lo numa linguagem (nas significações linguísticas em que se constitui e exprime) e atinge-nos através desta linguagem, que é”.

Há um campo epistemológico fértil para a reflexão da relação entre Linguagem e Direito. Em vista disso, percebem-se pensamentos divergentes e um constante tensionamento acerca da forma com que Direito e Linguagem se interagem. As abordagens são plúrimas e diferenciadas a partir da perspectiva de cada autor, o que contribui para enriquecer ainda mais as nossas ponderações sobre esta temática.

Neste sentido, trazemos as contribuições do pensador alemão Jürgen Habermas que tem contribuído para as discussões que tratam a linguagem enquanto uma problemática para o mundo jurídico. O filósofo criou a teoria da ação comunicativa e possibilitou as Ciências Jurídicas e Filosofia da Linguagem uma nova perspectiva que critica o racionalismo positivista e linguístico (HABERMAS, 1988, p. 79)

Habermas articula três conceitos: linguagem, racionalidade e ação; tais premissas devem ser analisadas pelos aspectos emancipatórios e democráticos onde o Direito exerce um papel fundamental. Deste modo, a teoria do agir comunicativo, desenvolvida por Jürgen Habermas - com base na noção de razão comunicativa torna-se muito relevante para os estudos que unem Linguagem e Direito, visto que, destaca o papel de integração social que estas ciências preceituam e que, consequentemente, legitimam a democracia e o acesso à justiça. 
Habermas postula então, a partir dos argumentos metodológicos expostos acima, a necessidade de mudança de paradigma da análise da razão de uma "filosofia da consciência" para uma "filosofia da linguística". A filosofia linguística assim proposta, entretanto, não considera suficiente a posição do semanticismo (de uma análise formal das frases) para elucidar a questão da razão através da linguagem. Ela estaria limitada a relação que se estabelece entre linguagem e mundo, sem levar em conta as relações que se estabelecem entre os sujeitos, quando se utilizam da linguagem para refere-se ao mundo. Habermas está interessa no uso de sentenças com uma intenção comunicativa. Por este motivo é que ele vai sugerir uma segunda "guinada", a "guinada teórico-comunicativa (ARAGÃO.1997, p.27)

Para Habermas, o princípio democrático propõe que as normas legítimas são aquelas que possuem aceitabilidade pelos membros da comunidade e que a linguagem associada a racionalidade comunicativa se constitui como dimensão primordial para a existência do Direito, consequentemente, a ação comunicativa em prol do entendimento se mostra como caminho necessário para se alcançar a busca pelo um Estado Democrático de Direito.

Estamos vivenciando cada vez mais a necessidade de compreender o Direito associado aos aspectos linguísticos, cujas complexidades semântica, sintática e pragmática requerem dos profissionais que atuam nas ciências jurídicas, em especial, dos magistrados uma atuação e posturas diferenciadas que vão muito além das questões que ultrapassam o seu cotidiano, que por muitas vezes, se mostram demasiadamente técnicos e burocráticos.

Pela perspectiva positivista da Linguagem e da Ciência Jurídica, destacamos o doutrinador Miguel Reale. Na obra intitulada "Lições Preliminares de Direito", o autor preleciona "os juristas falam uma linguagem própria e devem ter orgulho de sua linguagem multimilenar, dignidade que bem poucas ciências podem invocar”. E ressalta para os estudantes iniciantes "é necessário, pois, que dediquem a maior atenção à terminologia jurídica, sem a qual não poderão penetrar no mundo do Direito”. (MIGUEL REALE 1994, p. 07).

Reale promove o entendimento de que "o conhecimento da linguagem Jurídica, especialmente, da terminologia jurídica como condição essencial para penetrar no mundo do Direito", posto isto, apresentamos a maneira peculiar em que o ilustre teórico entendia a linguagem. Muitos consideram tais teses ultrapassadas e realmente é difícil sustentar esta tese na contemporaneidade, visto ser pacificado o caráter social da linguagem e das Ciências Jurídicas.

Por este viés, nos debruçamos nos seguintes questionamentos: Será, realmente, necessário mantermos, no campo da Ciência Jurídica, essa linguagem multimilenar que Reale 
defende? Em que medida, esta linguagem inacessível tem contribuído para universalização do acesso à justiça e à cidadania? Por que a linguagem Jurídica ainda é vista como uma "dignidade que bem poucas ciências podem invocar?

A partir destas inquietações podemos entender que é visível a percepção de que a linguagem jurídica é uma ferramenta dotada de uma técnica bastante complexa. Neste sentido, não podemos deixar de ressaltar que o pensamento do renomado doutrinador anteriormente mencionado vai ao encontro do aspecto do positivismo lógico em que surgiu a linguagem jurídica, partindo da suposta premissa que a terminologia jurídica rebuscada e inacessível seria o melhor caminho para o desenvolvimento das ideias e da prática jurídica. Afinal, a linguagem jurídica age como o aparato de comunicação que o Estado - e aqueles que o compõem - possui para legitimar seus atos através da coerção.

Em inúmeros casos, o poder das palavras e o poder sobre as palavras são poderes políticos; a rigor, o poder político é em grande parte um poder pelas palavras, na medida em que as palavras são instrumentos de construção da realidade. E já que a política é uma luta sobre os princípios de visão e de divisão do mundo social, o fato de impor uma nova linguagem a respeito do mundo social é, em grande parte, mudar a realidade. (BOURDIEU,2014. p.432).

Segundo (Gnerre, 1998, p. 22) "a linguagem constitui o arame farpado mais poderoso para bloquear o acesso ao poder". Ainda preleciona o autor:

[...] o aspecto específico da linguagem usada nos documentos jurídicos é semelhante ao fenômeno linguístico das linguagens especiais, constituídas em geral de léxicos efetivamente especiais usados nas estruturas gramaticais e sintáticas das variedades linguísticas utilizadas na comunidade. A função central de todas as linguagens especiais é social: elas têm um real valor comunicativo, mas excluem da comunicação as pessoas de comunidades linguísticas externas ao grupo que usa a linguagem especial e, por outro lado, têm a função de reafirmar a identidade dos integrantes do grupo reduzido que tem a linguagem especializada. (GNERRE 1998, p. 22),

Há muito tempo, a linguagem enquanto produto da cultura do homem vem despertando interesse de estudiosos de diferentes áreas do saber, que buscam compreendê-la sob os mais diversos ângulos. O interesse pela linguagem é muito antigo, expresso por mitos, lendas, cantos, rituais ou por trabalhos eruditos que buscam conhecer essa capacidade humana. Segundo Petter (2008, p. 12-13), remontam ao século IV A.C, os primeiros estudos sobre a linguagem". 
Importa ressaltar que somente sob a perspectiva metafórica da palavra, nos referimos à linguagem animal. "Se os animais têm sistemas de comunicação, trata-se de sistemas muito rudimentares, insuscetíveis de aperfeiçoamento". (PEDRO LUFTE, 2007, p. 12).

Mas enfim, o que é linguagem? Segundo Sapir (1980, p. 14), a linguagem "é um método puramente humano e não-instintivo de comunicação de ideias, emoções e desejos por meio de um sistema de símbolos voluntariamente produzidos. Entre eles, avultam primacialmente os símbolos auditivos, emitidos pelos chamados 'órgãos da fala”.

Marilena Chauí, importante filósofa brasileira, em sua obra intitulada "Convite à Filosofia", nos traz uma excelente reflexão sobre a linguagem pelas perspectivas de Aristóteles e Platão. Inicialmente, a autora destaca a máxima Aristotélica de que o homem é "um animal político", no sentido de social e cívico e, principalmente, em virtude do poder da linguagem que é inerente ao homem. Em sua referência, através do pensamento do filósofo Aristóteles, a autora distingue a manifestação do homem com outros animais, pois ao homem lhe é dado o poder da palavra, no sentido grego "logos" com ela, exprime o bom e o mau, o justo e o injusto e aos demais animais, apenas, a voz, no sentido "phoné" e com ela exprimem dor e prazer. (CHAUÍ, 200).

Prosseguindo na apreciação da autora sobre a importância da linguagem, a autora ressalta "desde que um homem foi reconhecido por outro como um ser sensível, pensante e semelhante a si próprio, o desejo e a necessidade de comunicar-lhe seus sentimentos e pensamentos fizeram-no buscar meios para isso". Chauí, fazendo referência a Platão em seu diálogo Fedro:

[...] Platão dizia que a linguagem é um phármakon. Essa palavra grega (da qual vem nosso vocábulo farmácia) [...] possui três sentidos principais: remédio, veneno e cosmético. Ou seja, Platão considerava que a linguagem pode ser um medicamento ou um remédio para o conhecimento, pois, pelo diálogo e pela comunicação, conseguimos descobrir nossa ignorância e aprender com os outros. Pode, porém, ser um veneno quando, pela sedução das palavras, nos faz aceitar fascinados com o que vimos ou lemos, sem que indaguemos se tais palavras são verdadeiras ou falsas. Enfim, a linguagem pode ser cosmético, maquiagem ou máscara para dissimular ou ocultar a verdade sob as palavras. A linguagem pode ser conhecimentocomunicação, mas também pode ser encantamento-sedução. (CHAUÍ, 2008, p. 148)

Além disso, a linguagem é vista como um elemento estruturador da relação do homem com a realidade, de manutenção de poder e formas de dominação. É uma capacidade inata do 
ser humano, tendo em vista que é um dom específico do animal racional. A linguagem é, portanto, uma faculdade inata que possibilita aos sujeitos expressarem os seus pensamentos, sentimentos através de um código de signos.

Segundo KRAMER (1993, p. 103) “a linguagem é produção humana acontecida na história; produção que construída nas interações sociais, nos diálogos vivos - permite pensar as demais ações e a si própria, constituindo a consciência". Assim, a linguagem é um "lugar" de interação, capaz de possibilitar aos sujeitos as mais diversas práticas comunicativas.

Sendo assim, salienta PETRI (2008, p. 2), "a língua funciona como um elemento de interação entre o indivíduo e a sociedade em que ele atua". É um instrumento de comunicação que permite a convivência e o desenvolvimento do homem em sociedade.

\subsection{Tecnicismo da Linguagem Jurídica}

Sabe-se que a palavra tem fundamental importância no dia a dia de todas as profissões, tornando-se imprescindível a qualquer área de atuação. No mundo da Ciência Jurídica, não seria diferente. Ademais, a palavra escrita ou oral se constituem como principais recursos de trabalho que se dispõe ao profissional do Direito (CARMO, 2009, p. 203). Ainda ratificando a importância da palavra na vida dos profissionais que atuam no Direito Xavier pontua:

Jamais, como em Direito, o conhecido refrão popular "te pego pela palavra" teve
tantos foros de verdade. Em qualquer causa, especialmente naquela onde houver
incerteza quanto à decisão, a experiência recomenda cautela na escolha das palavras,
para que o feitiço não vire contra o feiticeiro [...] (XAVIER, 2003, p. 11).

Há, portanto, uma notável preocupação de que os construtores do Direito devem procurar melhorar seu vocabulário, procurando utilizar sempre o termo mais adequado ao contexto sócio comunicativo. Os vocábulos técnicos e a linguagem precisam exercerem a função de contribuir para compreensão do Direito e para a eficácia do ato da comunicação jurídica.

Partindo dessa premissa, consideramos que o uso do vocabulário jurídico pelos profissionais da área faz-se necessário, entretanto, que este não deve ser utilizado para confundir a comunicação. "No Direito, é ainda mais importante o sentido das palavras porque qualquer sistema jurídico, para atingir plenamente seus fins, deve cuidar do valor nacional do 
vocabulário técnico e estabelecer relações semântico-sintáticas harmônicas e seguras na organização do pensamento". (OTHON GARCIA 1975, p. 135).

Todas as áreas do saber se constituí pautadas em um vocabulário específico, que são denominados de termos técnicos. Desta forma, podemos mencionar que onde quer que exista uma ciência, existe uma linguagem correspondente. Neste sentido, menciona Petri (2008, p.29) "há uma linguagem jurídica porque o Direito dá um sentido particular a certos termos. O conjunto desses termos forma o vocabulário jurídico".

A utilização de termos técnicos, muitas vezes, traz ao enunciado jurídico precisão e clareza e serve, em tese, para salvaguardar a segurança jurídica. Damião e Henrique, (2010, p.37) fazem a seguinte definição para o termo vocabulário jurídico "é o uso do falante, é a seleção, é o emprego de palavras pertencentes ao léxico para realizar a comunicação humana".

É através do vocabulário que podemos perceber a personalidade do homem e dos seus conhecimentos linguísticos adquiridos em sociedade, neste sentido, é de suma importância aos usuários de uma língua o enriquecimento de seu inventário vocabular através das práticas de leitura e escrita, facilitando assim a sua tarefa comunicativa e redacional.

A clareza das ideias está relacionada com o uso da clareza e precisão das palavras, deste modo, "a função das palavras é transmitir um sentido, sob pena de elas não terem razão de existir. A significação associa um ser, um fato, uma ideia um signo capaz de evocá-los" (XAVIER, 2003, p. 12).

\footnotetext{
"No Direito, é ainda mais importante o sentido das palavras porque qualquer sistema jurídico, para atingir plenamente seus fins, deve cuidar do valor nacional do vocabulário técnico e estabelecer relações semântico-sintáticas harmônicas e seguras na organização do pensamento". (OTHON GARCIA 1975, p. 135)
}

Terminologia é o conjunto de palavras técnicas pertencentes a uma ciência, é interessante ressaltar, que esta não abriga todas as palavras, mas somente aquelas que constituem a linguagem especializada Segundo a definição do dicionário Houaiss terminologia é o "conjunto de termos específicos ou sistema de palavra usado numa disciplina particular (por exemplo, a terminologia da botânica, da marinharia, da matemática); nomenclatura". (HOUAISS e VILLAR, 2001, p. 2702). 
Na terminologia jurídica, os termos têm significação própria, são invariáveis, sem possibilidade de sinonímia o que, certamente, traz aos enunciados jurídicos precisão e clareza. "Com efeito, trata-se de um vocabulário técnico, profissional, que se restringe à ambiência jurídica, onde as palavras assumem conotações próprias.” (XAVIER, 1992, p. 11)

Torna-se mister destacar que os termos técnicos são necessários à medida que remetem a situações e conceitos específicos do Direito. "O uso da terminologia adequada torna possível à compreensão de um texto especializado, principalmente o técnico-científico, mesmo por quem não domine completamente o idioma que foi empregado." (ANDRADE, 2001, p.199)

Contudo, o maior problema em fazer uso da terminologia jurídica está pautado no uso de linguagem específica, pois, esta contribui para a comunicação entre os especialistas, mas sim, quando entre palavras com o mesmo significado, escolhe-se aquela menos conhecida da maioria das pessoas para materializar o texto oral ou escrito. "a linguagem deficiente é duramente punida em juízo. Outro ponto que merece destaque é o uso excessivo do arcaísmo que faz com que, muitas vezes, o receptor da mensagem não a entenda, uma vez que o texto se torna inteligível, dificultando assim a clareza, compreensão e progressão textual.

De acordo com Rodriguez (2004, p. 32), “[...] o arcaísmo ou preciosismo significa, para nós, aquela palavra de sentido obscuro, buscada no dicionário pelo próprio autor, para tornar sua linguagem aparentemente mais culta, mais rebuscada. É palavra de uso mais raro".

É comum encontrarmos nos textos jurídicos os estrangeirismos e latinismos desnecessários utilizados pelos profissionais da área jurídica com a intenção de demonstrar conhecimento, porém, o uso destas expressões, podem trazer ao leitor que não tem conhecimentos técnicos uma incompreensão textual, dificultando assim o acesso comunicação e à justiça.

De um lado, não podemos desconsiderar que há expressões latinas que já estão consagradas e incorporadas no imaginário social e, consequentemente, que são conhecidas pela sociedade, pois, são incorporadas ao dia a dia dos profissionais do Direito ou mesmo pela própria mídia que divulga certas expressões, tornando-as corriqueiras, tais como "periculum in mora" (perigo da demora), "habeas corpus" (que tenhas o teu corpo), "ad judicia" (para o juízo), dentre outras. 
Por outro lado, o que defendemos não é a retirada de todos os termos técnicos, ou expressões em latim, mas o uso excessivo e constante de expressões desnecessárias que podem ser substituídas facilmente por termos correspondentes na língua portuguesa. Este hermetismo, inerente à linguagem jurídica provoca um obstáculo, que afasta o Poder Judiciário da sociedade, ainda mais se considerarmos que o sistema educacional brasileiro ainda apresenta resultados considerados muito fracos, sendo assim, como se pode esperar que uma grande parcela da população, que não possui um grau satisfatório de instrução compreenda e participe de forma consciente das decisões tomadas pelo Poder Judiciário e que possa lutar e buscar pelos próprios direitos?

Assim, defendemos por desnecessário o uso excessivo de juridiquês' que são usados como adornos, enfeites na linguagem jurídica. Consideramos estes enfeites desvios da linguagem jurídica e que se dão de duas formas, a saber: o preciosismo empregado na linguagem jurídica e os problemas que rondam a construção textual na área do direito. Em sua grande maioria estes termos já são termos ultrapassados e de pouco uso até mesmo na linguagem técnica. No entanto, ainda é muito comum notarmos resistência de alguns profissionais da Ciência Jurídica em abrir mão do uso excessivo de juridiquês, fato que demostra pouca preocupação com objetividade e clareza do texto jurídico e manutenção do conservadorismo linguístico.

É interessante destacar que juridiquês não é tecnicismo, muitas vezes, o emprego de termos técnicos se faz necessário. Diferentemente dos termos técnicos, estes termos impedem a compreensão adequada do que está sendo proferido, até mesmo dos profissionais da área do Direito, prejudicando assim, o processo de comunicação.

Para Maciel o “juridiquês é um dos responsáveis pela lentidão da justiça brasileira.

Há transcrição exagerada de textos de leis, doutrinas e jurisprudências. Desconsidera o advogado, que um par de teses favoráveis ao seu pedido já é suficiente. O juiz nunca lerá integralmente uma petição extensa. Para conseguir despachar inúmeros processos diariamente, é obrigado a dispensar o supérfluo e se ater apenas ao essencial. Ao exagerar em citações, o peticionário estará somente desperdiçando tempo e engrossando os autos processuais. A economia textual é palavra de ordem na órbita da justiça e elemento mor para a celeridade dos processos. Ater-se ao formalmente necessário é meia causa ganha pelo profissional do direito. (MACIEL, 2007, p. 1).

Percebe-se que é imprescindível que se busque a clareza do texto e o uso excessivo de "juridiquês" não é resultado do uso dos termos técnicos, e sim consequência do excesso de 
formalismo que circunda o meio jurídico Usar a linguagem mais clara, compreensível pelo maior número de pessoas possível é tornar o Direito mais transparente e acessível. Como bem destacam Damião e Henriques (2000, p. 103), “tempos atrás, alguns se deleitavam em compor textos jurídicos impregnados de termos rebuscados. Hoje, não é assim, embora o discurso jurídico continue técnico, com as características do jargão que lhe é próprio".

Neste sentido, todos os termos de exagerados e incompreensíveis utilizados pelos profissionais do direito, com uma forma rebuscada de apresentação são, atualmente, contraditórios a toda simplificação da linguagem exibida pelos mais diversos meios de comunicação. Urge, portanto, a clara a necessidade de um vocabulário mais simples, clara e objetiva, que tenha o intuito de aproximar a sociedade da justiça e da prestação jurisdicional.

\section{A LINGUAGEM COMO SUPORTE BASILAR DE ACESSO À JUSTIÇA}

Exercer a cidadania plena é tornar evidente à proporção dos direitos civis, políticos e sociais conquistados pelos cidadãos, notabiliza-se, também, que, consequentemente, quando o sujeito exerce a cidadania, torna-se visível o seu sentimento de satisfação em relação à igualdade perante a lei.

Como bem elenca Boaventura de Souza Santos "A igualdade dos cidadãos perante a lei passou a ser confrontada com a desigualdade da lei perante os cidadãos, uma confrontação que em breve se transformou num vasto campo de análise sociológica e de inovação social centrado na questão do acesso diferencial ao direito e à justiça por parte das diferentes classes e estratos sociais" (SANTOS, 1988, p. 16).

Com o advento da tecnologia e democratização ao acesso à informação, o poder judiciário aprimora cada vez mais os mecanismos de efetivação e acesso à justiça. É comum a aproximação dos cidadãos as páginas dos tribunais que tem processo em andamento, sem muita burocracia. Porém, faz-se oportuno a compreensão da linguagem jurídica escrita nos documentos para que se possa entender a tramitação do processo.

Em linhas gerais, reconhece-se, que a linguagem jurídica deva ser compreensível e esclarecedora as partes do litígio para que os cidadãos possam entender as decisões judiciárias, e consequentemente, ter maior acesso ao Direito.

A democratização implica numa aproximação do direito da realidade que procura representar e sobre a qual pretende agir, implica na adoção de uma postura que não cria divisões separações entre universos discursivos, quanto a síntese a simplicidade podem significar mais. (Bittar, 2010, p. 390). 
De acordo com Hess (2004, p. 01) o conceito de acesso à justiça é um atributo universal e que as garantias deste acesso se desenvolveram e se se consolidaram na mesma proporção dos ideais de Estado Democrático de Direito, proporcionando assim, cidadania plena a todos. Há uma multiplicidade de sentidos da expressão acessos à justiça. Nesta ordem, verifica-se que:

\begin{abstract}
A expressão 'acesso à justiça' é reconhecidamente de difícil definição, mas serve para determinar duas finalidades básicas do sistema jurídico - o sistema pelo qual as pessoas podem reivindicar seus direitos e/ou resolver seus litígios sob os auspícios do Estado. Primeiro, o sistema ser igualmente acessível a todos; segundo, ele deve produzir resultados que sejam individual e socialmente justos. [...] uma premissa básica será a de que a justiça social, tal como desejada por nossas sociedades modernas, pressupõe o acesso efetivo. (CAPPELLETTI, 2002, p.08)
\end{abstract}

Consoante a Hess (2004, p.01) quem tem como premissa o conceito de acesso à justiça como um atributo universal e "que as garantias deste acesso se desenvolveram e se se consolidaram na mesma proporção dos ideais de Estado Democrático de Direito, proporcionando assim cidadania plena a todos".

Não podemos deixar de olvidar que a garantia constitucional do acesso à justiça também denominada de princípio da inafastabilidade da jurisdiççao está consagrada no artigo $5^{\circ}$, inciso XXXV da Constituição Federal de 1988. O acesso a justiça é, portanto, um principio norteador do poder judiciário e pode ser considerado como pilar estrutural e o mais básico dos direitos dos cidadãos.

Neste sentido, o termo acesso à justiça foi historicamnete construído à medidade que os sujeitos possam intregir e compreenderem ao menos a estrurtura básica do sistema jurídico. Assim sendo, " a expressão acesso à justiça vai muito além de ser ter uma lide nas mãos do daqueles que representam o poder judiciário, visto que, como mencionado anteriomente, todos os cidadãos brasileiros têm seus direitos resguardados e garantidos na Carta Magna.

Neste iterim, a linguagem e o Direito são áreas de conhecimento que fazem parte da vida dos cidadãos e que têm como premissa básica serem acessíveis a sociedade, são produtos de construção sócio-cultural substanciais à efetivação do acesso à justiça e que devem, portanto, estarem ao alcance de todos, visto que, são intrumentos oportunos para que os sujeitos possam engajarem socialmente. Sendo assim, a utlização de uma linguagem 
rebuscada, que prioriza palavras ultilizadas em outra língua estrangeiras não condiz com o papel diálogico da linguagem.

\section{CONSIDERAÇÕES FINAIS}

A linguagem jurídica escrita ou oral deve ser concebida enquanto produto da interação social, visto que, em um Estado Democrático de Direito, a função primordial da linguagem é a comunicação. Portanto, a premissa básica da pesquisa é de que o ideal é utilizar uma linguagem acessível ao público leigo, no intuito de aproximar a sociedade do Poder Judiciário e aprimorar a prestação jurisdicional e a concretização da Justiça.

Tona-se oportuno destacar que os termos técnicos são necessários, mas defendemos, primordialmente, encontrarmos o ponto de equilíbrio entre simplicidade e precisão. Dessa forma, combatemos as representações imagéticas discursivas de que deve ser mantido os mecanismos de conservação de uma linguagem “multimilenar” defendida por Miguel Reale.

Em síntese, na análise da relação entre linguagem e Ciência Jurídica encontramos dois polos de atuação os defensores do conservadorismo linguístico jurídico e a concepção contemporânea que nos leva a perceber a linguagem social e interacional em que as tensões ideológicas se manifestam. Restando ao leitor escolher o seu posicionamento político, ideológico e social quanto a perspectiva que irá adotar.

No entanto, vale destacar que a perspectiva de que a linguagem jurídica obsoleta, repleta de arcaísmo e latinismo não condiz com os princípios constitucionais de igualdade e acesso à justiça. Posto isto, constata-se maior eficácia jurídica, quando há iniciativa do legislador e dos profissionais do Direito a redigirem as sentenças com clareza e objetividade.

\section{REFERÊNCIAS}

BENVENISTE, Emile. Curso de Linguística Geral. Campinas: Pontes, 1994. Vol. 1 e 2.

BOURDIEU, Pierre. Sobre o Estado. Tradução Rosa Freire D'Aguiar. $1^{\text {a }}$ ed. Companhia das Letras, São Paulo: 2014.

BITTAR, Eduardo Carlos Bianca. Linguagem Jurídica. 5º ed., São Paulo: Saraiva, 2010.

CAPPELlETTI, Mauro; GARTH, Bryant. Acesso à justiça. Trad. de Ellen Gracie Northfleet. Porto Alegre: Sergio Antonio Fabris, 2002. 
CARMO, Júlio Bernardo do. Técnica de redação de sentença e de conciliação no juízo monocrático. Revista do Tribunal Regional do Trabalho da $3^{\mathbf{a}}$ Região, Belo Horizonte, v. 31, n. 61, p. 203-222, Jan./Jun.2000. Disponível em: http://www.mg.trt.gov.br/escola/download/revista/rev_61/Julio_Carm pdf. Acesso em: 23 out. 2019. CASTENHEIRA NEVES, Antônio. Metodologia Jurídica. Problemas Fundamentais. Coimbra Editores, 1993.

CHAUÍ, Marilena. Convite a Filosofia. São Paulo: Editora Ática, 2000. Coelho, Teixeira. COSTA, M. D. A comunicação e o acesso à Justiça. Revista do Centro de Estudos Judiciários, Brasília, n. 22, p. 13-19, jul./set. 2003.

DINIZ, M. Helena. Compêndio de introdução à ciência do Direito. 12 ed. São Paulo: Saraiva, 2000.

GONÇALVES, Wilson José. Comunicação Jurídica: perspectiva da semiótica. Campo Grande: UCDB, 2002.

KRAMER, S. Por entre as pedras: arma e sonho na escola. São Paulo: Ática, 1993.

NASCIMENTO, Edmundo Dantes. Linguagem Forense.12.ed. São Paulo: Saraiva, 2009.

NUNES, Rizzatto. Manual de introdução ao estudo do direito. São Paulo: Ed. Saraiva, 2006.

PASOLD, Cesar Luiz. Metodologia da Pesquisa Jurídica: Teoria e Pratica. 12ed. rev. São Paulo: Conceito Editorial, 2011.

PETRI, Maria José Constantino. Manual de Linguagem Jurídica. São Paulo: Saraiva, 2008.

PETTER, Margarida. Uma breve história do estudo da linguagem. In: Fiorin, José Luiz (org). Introdução à linguística: I objetos teóricos. São Paulo: 2008, contexto.

REALE, Miguel. Lições Preliminares de Direito. 21ª ed., São Paulo: Saraiva, 1994.

TEIXEIRA, I. C. Os professores como sujeitos sócio-culturais In: DAYRELL, J. (Org.). Múltiplos olhares sobre a educação e a cultura. Belo Horizonte: Ed. UFMG, 1996.

WAMBIER, Teresa Arruda Alvim; RODRIGUES, Luiz. Pequeno ensaio sobre a função da linguagem e o fenômeno jurídico. Revista Jurídica Consulex, Ano XI, n. 240, 15.01.07.

XAVIER, Ronaldo Caldeira Xavier. Português no Direito: Linguagem Forense. Rio de Janeiro: Forense, 2002.

DESCARTES, René. Discurso sobre o método. Porto Alegre: L\&PM, 2009.

FOUCAULT, Michel. As palavras e as coisas. 8 ed. São Paulo: Martins Fontes, 2000.

FOUCAULT, Michel. A verdade e as formas jurídicas. 3 ed. Rio de Janeiro: Nau, 2002. 
GADAMER, Hans-Georg. Verdade e método: traços fundamentais de uma hermenêutica filosófica. 10 ed, Petrópolis: Vozes, 2008.

GNERRE, M. Linguagem, escrita e poder. 4. ed. São Paulo: Martins Fontes, 1998.

HABERMAS, Jurgen. Teoria de la Acción Comunicativa. Trad. Manuel Jiménez Redondo. Madrid: Taurus, 1988. V. I e II.

HABERMAS, Jurgen Consciência Moral e agir comunicativo. Trad. Guido A. de Almeida. Rio de Janeiro: Tempo Brasileiro, 10989.

HEIDEGGER, Martin. Ser e tempo. Parte I. 15 ed. Petrópolis: Vozes, 2005.

HESS, Heliana Maria Coutinho. Acesso à justiça por reformas judiciais. Campinas, SP: Millennium Editora, 2004.

HEIDEGGER, Martin. A caminho da linguagem. 4 ed. Petrópolis: Vozes: 2008.

MASCARO, Alysson. Filosofia do Direito. São Paulo: Atlas, 2010.

RABINOW, Paul; DREYFUS, Hubert. Michel Foucault: Uma trajetória filosófica. Rio de Janeiro: Forense, 1995.

ROCHA, Luiz Alberto G. S. A Escola Francesa e as Definições de Poder: Georges Burdeau e Michel Foucault. Revista Mestrado em Direito (UNIFIEO. Impresso), v. 10, p. 97-113, 2010 .

SAPIR, E. A Linguagem. São Paulo, Perspectiva, 1980.

SANTOS, Boaventura de Sousa. Introdução à Sociologia da Administração da Justiça. Revista Crítica de Ciências Sociais. Nº, Novembro de 1998. p. 16.

SILVA, Francisco Paulo da. Articulações entre poder e discurso em Michel Foucault. In: SARGENTINI, Vanice; NAVARRO-BARBOSA, Pedro (org.). Foucault e os domínios da linguagem: discurso, poder, subjetividade. São Carlos: Claraluz, 2004.

XAVIER, Ronaldo Caldeira Xavier. Português no Direito: Linguagem Forense. Rio de Janeiro: Forense, 2002. 